University of Nebraska - Lincoln

DigitalCommons@University of Nebraska - Lincoln

Jay F. Storz Publications

Papers in the Biological Sciences

6-14-2013

\title{
Epistasis Among Adaptive Mutations in Deer Mouse Hemoglobin
}

Chandrasekhar Natarajan

University of Nebraska-Lincoln, chandrasekhar.natarajan@unl.edu

Noriko Inoguchi

University of Nebraska-Lincoln, ninoguchi2@unl.edu

Roy E. Weber

Aarhus University, Denmark, roy.weber@biology.au.dk

Angela Fago

Aarhus University, Denmark, angela.fago@biology.au.dk

Hideaki Moriyama

University of Nebraska-Lincoln, hmoriyama2@unl.edu

See next page for additional authors

Follow this and additional works at: https://digitalcommons.unl.edu/bioscistorz

Natarajan, Chandrasekhar; Inoguchi, Noriko; Weber, Roy E.; Fago, Angela; Moriyama, Hideaki; and Storz, Jay F., "Epistasis Among Adaptive Mutations in Deer Mouse Hemoglobin" (2013). Jay F. Storz Publications. 56.

https://digitalcommons.unl.edu/bioscistorz/56

This Article is brought to you for free and open access by the Papers in the Biological Sciences at DigitalCommons@University of Nebraska - Lincoln. It has been accepted for inclusion in Jay F. Storz Publications by an authorized administrator of DigitalCommons@University of Nebraska - Lincoln. 


\section{Authors}

Chandrasekhar Natarajan, Noriko Inoguchi, Roy E. Weber, Angela Fago, Hideaki Moriyama, and Jay F. Storz 


\title{
Epistasis Among Adaptive Mutations in Deer Mouse Hemoglobin
}

\author{
Chandrasekhar Natarajan, ${ }^{1}$ Noriko Inoguchi, ${ }^{1}$ Roy E. Weber, ${ }^{2}$ Angela Fago, ${ }^{2}$ Hideaki \\ Moriyama, ${ }^{1}$ and Jay F. Storz ${ }^{1}$ \\ 1. School of Biological Sciences, University of Nebraska, Lincoln, NE 68588, USA \\ 2. Zoophysiology, Department of Bioscience, Aarhus University, DK-8000 Aarhus, Denmark \\ Corresponding author — Jay F. Storz, email jstorz2@unl.edu
}

\begin{abstract}
Epistatic interactions between mutant sites in the same protein can exert a strong influence on pathways of molecular evolution. We performed protein engineering experiments that revealed pervasive epistasis among segregating amino acid variants that contribute to adaptive functional variation in deer mouse hemoglobin $(\mathrm{Hb})$. Amino acid mutations increased or decreased $\mathrm{Hb}-\mathrm{O}_{2}$ affinity depending on the allelic state of other sites. Structural analysis revealed that epistasis for $\mathrm{Hb}-\mathrm{O}_{2}$ affinity and allosteric regulatory control is attributable to indirect interactions between structurally remote sites. The prevalence of sign epistasis for fitness-related biochemical phenotypes has important implications for the evolutionary dynamics of protein polymorphism in natural populations.
\end{abstract}

$\mathrm{N}$ onadditive interactions between mutations (epistasis) can exert a strong influence on the rate and direction of evolutionary change $(1,2)$. Insights into mechanisms of epistasis between beneficial mutations can reveal the causes of constraints on adaptive protein evolution (3-10). Mechanisms of epistasis are often best revealed through detailed examinations of interactions between amino acid mutations in the same protein that contribute to variation in a measurable biochemical phenotype (7, 9-15). Such studies are especially relevant to our understanding of evolutionary process when genetically based changes in the measured phenotype contribute to variation in fitness under natural conditions.

We investigated the nature of epistatic interactions between adaptive mutations in the hemoglobin $(\mathrm{Hb})$ of deer mice (Peromyscus maniculatus). Deer mice that are native to high altitude have evolved an elevated $\mathrm{Hb}-\mathrm{O}_{2}$ affinity relative to lowland conspecifics (16-18), and this modification of protein function contributes to an adaptive enhancement of whole-animal physiological performance under hypoxia $(19,20)$. Comparisons between highland deer mice from the Rocky Mountains and lowland deer mice from the Great Plains revealed genetic differences in $\mathrm{Hb}$ $\mathrm{O}_{2}$ affinity that are attributable to the independent or joint effects of 12 amino acid polymorphisms: 8 mutations in the $\alpha$-chain subunits of the $\alpha_{2} \beta_{2} \mathrm{Hb}$ tetramer, and 4 mutations in the $\beta$-chain subunits.
These 12 amino acid polymorphisms exhibit pronounced altitudinal shifts in allele frequency, and population genetic analyses of nucleotide variation in the $\alpha$ and $\beta$-globin genes revealed evidence for divergent selection between deer mouse populations that are native to different elevations $(18,21-23)$.

Structural variation in deer mouse $\mathrm{Hb}$ has a modular organization that reflects the linkage arrangement of the 12 amino acid polymorphisms. Within the $\alpha$-chain subunit, five amino acid replacements are located in exon 2 of the underlying gene, and the remaining three replacements are 1ocated in exon 3. Polymorphic sites within the same exon are in nearly complete linkage disequilibrium (LD) with one another, but intragenic recombination has produced a partial uncoupling between the two exons $(21,23)$. The two most common $\alpha$-globin allele classes are distinguished from each other by eight amino acid replacements at sites 50, 57, 60, 64, 71, 113, 115, and 116 (Figure S1A). The four amino acid polymorphisms in the $\beta$-globin gene are also in nearly complete LD with one another $(18,22)$. The two most common $\beta$-globin allele classes are distinguished from each other by four amino acid replacements at sites 62, 72, 128, and 135 (Figure S1B). Thus, in deer mouse populations, most of the naturally occurring variation in $\mathrm{Hb}$ structure is captured by combinatorial permutations of allelic variants at three loci: $\alpha$-globin exon 2 , $\alpha$-globin exon 3 , and $\beta$-globin.
We used site-directed mutagenesis to engineer all eight combinations of the $\alpha$ and $\beta$-chain variants in recombinant $\mathrm{Hb}$ $(\mathrm{rHb})$, and we measured $\mathrm{O}_{2}$-binding properties of the purified proteins (24). In addition to the chimeric multipoint mutants, we also engineered 10 additional singleand double-mutant $\mathrm{rHbs}$ to measure the functional effects of specific point mutations individually and in pairwise combination. We synthesized rHbs representing the two most common variants from high- and low-altitude populations, designated "HH-H" and "LL-L," respectively (the first two letters denote the separate $\alpha$-chain subdomains encoded by exons 2 and 3 , and the third letter denotes the $\beta$-chain subunit). To test for epistasis, we also synthesized rHbs representing the remaining six combinations of $\mathrm{H}$ and L-type alleles at each of the three loci (Figure 1A). To examine variation in the allosteric regulation of $\mathrm{Hb}-\mathrm{O}_{2}$ affinity, we measured $\mathrm{O}_{2}$-binding properties of each $\mathrm{rHb}$ mutant in the presence and absence of the two principal allosteric effectors present in mammalian red blood cells: $\mathrm{Cl}^{-}$ions and 2,3-diphosphoglycerate (DPG). These effectors reduce $\mathrm{Hb}-\mathrm{O}_{2}$ affinity by preferentially binding and stabilizing deoxyHb, thereby shifting the allosteric equilibrium in favor of the low-affinity T-state quaternary structure. By using standardized concentrations of $\mathrm{Cl}^{-}$and DPG in the physiological range, we ensured that in vitro measurements were relevant to in vivo conditions (24). 
Our experiments revealed substantial variation in intrinsic $\mathrm{Hb}-\mathrm{O}_{2}$ affinity, as $P_{50}$ values (the $\mathrm{O}_{2}$ tension at $50 \%$ heme saturation) for stripped, cofactor-free rHbs ranged from 4.55 to 7.09 torr (Table 1). The high-altitude HH-H variant exhibited a $26 \%$ lower stripped $P_{50}$ (i.e., higher intrinsic $\mathrm{O}_{2}$ affinity) relative to the low-altitude LL-L variant (Table 1 ). $\mathrm{Hb}-\mathrm{O}_{2}$ affinity was reduced in the presence of $\mathrm{Cl}^{-}$ions (added as $0.1 \mathrm{M} \mathrm{KCl}$ ), in the presence of DPG at a twofold molar excess over tetrameric $\mathrm{Hb}$, and in the simultaneous presence of both effectors (Table 1). All rHbs exhibited cooperative $\mathrm{O}_{2}$ binding, and Hill coefficients ranged from 1.36 to 2.28 in the presence of $\mathrm{Cl}^{-}$and DPG.

Contrary to the expectations of an additive null model, the phenotypic effects of allelic substitutions $(\mathrm{L} \rightarrow \mathrm{H}$ and $\mathrm{H} \rightarrow \mathrm{L}$ ) at $\alpha$-globin exon $2, \alpha$-globin exon 3 , and $\beta$-globin were highly dependent on ge- netic background, as pairwise epistasis accounted for $40 \%$ of the variance in $P_{50}$ values in the absence of allosteric effectors and $90 \%$ in the simultaneous presence of $\mathrm{Cl}^{-}$and DPG (Table 1). In the presence of both allosteric effectors, the $\mathrm{HH} \alpha$-globin allele conferred an increased affinity on the $\beta \mathrm{L}$ background and a decreased affinity on the $\beta \mathrm{H}$ background. Similarly, the H-type $\beta$-globin allele conferred an increased affinity on the $\alpha$ LL background and a decreased affinity on the $\alpha \mathrm{HH}$ background. These are examples of sign epistasis (2), where the sign of the phenotypic effect of an allele is conditional on genetic background.

Because mammalian $\mathrm{Hb}$ is a heterotetramer $\left(\alpha_{2} \beta_{2}\right)$, epistatic interactions could involve closely linked sites in the same gene or sites in unlinked genes that encode different subunits of the protein. Intragenic (within-subunit) epistasis could stem from localized modifications of secondary or tertiary structure, whereas intergenic (between-subunit) epistasis could stem from allosteric transitions in quaternary structure between different oxygenation states of the $\mathrm{Hb}$ tetramer. Epistasis for $\mathrm{Hb}-\mathrm{O}_{2}$ affinity is mainly attributable to the suppressed DPG sensitivity of chimeric $\mathrm{rHb}$ variants that incorporate the products of $\alpha$ and $\beta$-globin alleles of unlike type $(\alpha \mathrm{HH}$ combined with $\beta \mathrm{L}$, and vice versa; Table 1 and Figure 1B). Although DPG sensitivity was suppressed in HH-L and LL-H, allosteric regulatory capacities of the chimeric rHbs were partially restored by reciprocally converting either of the two $\alpha$-chain subdomains to the type that matched the associated $\beta$-chain subunit: DPG sensitivity of the chimeric LL-H was partially restored by $\mathrm{L} \rightarrow \mathrm{H}$ substitutions at $\alpha$-globin exon 2 or exon 3, and reciprocally, DPG sensitivity of the chimeric HH-L was par-
A

\begin{tabular}{l|lllll|lll|llll|} 
& 50 & 57 & 60 & 64 & 71 & 113 & 115 & 116 & 62 & 72 & 128 & 135 \\
HH-H & Pro & Gly & Ala & Gly & Ser & His & Ala & Glu & Gly & Gly & Ala & Ala \\
HH-L & Pro & Gly & Ala & Gly & Ser & His & Ala & Glu & Ala & Ser & Ser & Ser \\
HL-H & Pro & Gly & Ala & Gly & Ser & Leu & Ser & Asp & Gly & Gly & Ala & Ala \\
HL-L & Pro & Gly & Ala & Gly & Ser & Leu & Ser & Asp & Ala & Ser & Ser & Ser \\
LH-H & His & Ala & Gly & Asp & Gly & His & Ala & Glu & Gly & Gly & Ala & Ala \\
LH-L & His & Ala & Gly & Asp & Gly & His & Ala & Glu & Ala & Ser & Ser & Ser \\
LL-H & His & Ala & Gly & Asp & Gly & Leu & Ger & Asp & Gly & Gly & Ala & Ala \\
LL-L & His & Ala & Gly & Asp & Gly & Leu & Ser & Asp & Ala & Ser & Ser & Ser
\end{tabular}

\section{B}

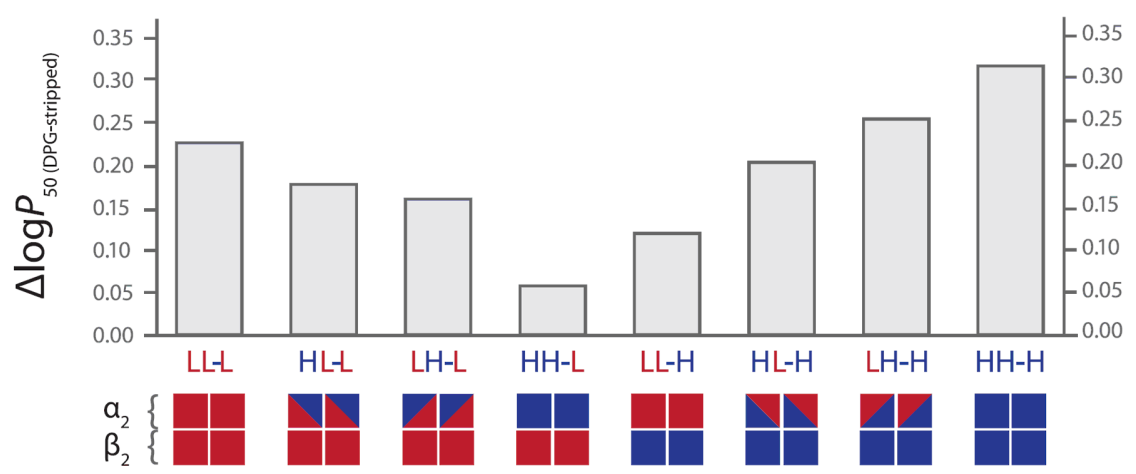

Figure 1. Structural and functional variation among recombinant deer mouse $\mathrm{Hbs}$ (rHbs). (A) rHbs representing all combinatorial permutations of allelic variants at $\alpha$-globin exon 2, $\alpha$-globin exon 3 , and $\beta$-globin. Shaded regions represent the products of low-altitude L-type alleles (red), and unshaded regions represent products of high-altitude $\mathrm{H}$-type alleles (blue). (B) Variation in the allosteric regulation of $\mathrm{Hb}-\mathrm{O}_{2}$ affinity by DPG. Sensitivity to DPG is indexed by the difference in logtransformed $P_{50}$ values between stripped $\mathrm{Hb}$ in the presence and absence of DPG.

Table 1. $\mathrm{O}_{2}$ affinities $\left(P_{50}\right.$, torr; mean \pm SEM) and allosteric properties of purified rHbs. Sensitivities to allosteric effectors are measured as the difference in log-transformed $P_{50}$ values in the presence and absence of each effector, individually and in combination. $V_{\mathrm{A}}$ and $V_{\mathrm{E}}$ are estimated components of additive and epistatic variance, respectively (24).

\begin{tabular}{|c|c|c|c|c|c|c|c|c|c|c|}
\hline \multirow{2}{*}{$P_{50}$ (torr) } & \multirow[t]{2}{*}{ LL-L } & IL-L & LH-L & IH-L & LL-H & IL-H & LH-H & $\mathrm{HH}-\mathrm{H}$ & $v_{\mathrm{A}}$ & \multirow[t]{2}{*}{$v_{E}$} \\
\hline & & $637+0.05$ & $709+055$ & $659+011$ & $525+009$ & $549+004$ & $632+015$ & $455+008$ & 0.597 & \\
\hline$+\mathrm{KCl}$ & $10.20 \pm 0.03$ & $12.55 \pm 0.41$ & $10.83 \pm 0.78$ & $12.88 \pm 0.27$ & $12.15 \pm 0.31$ & $11.18 \pm 0.30$ & $12.01 \pm 0.20$ & 47 & 0.0 & 0.949 \\
\hline$+D P G$ & $9.72 \pm 0.17$ & $9.64 \pm 0.12$ & $10.33 \pm 0.20$ & $7.54 \pm 0.25$ & $6.93 \pm 0.19$ & $8.84 \pm 0.26$ & $11.44 \pm 0.30$ & $9.53 \pm 0.27$ & 0.189 & 0.811 \\
\hline $\begin{array}{l}+\mathrm{KCl}+\mathrm{DPG} \\
\Delta \log P_{50}\end{array}$ & $10.46 \pm 0.30$ & $11.21 \pm 0.33$ & $12.51 \pm 0.59$ & $8.63 \pm 0.21$ & $7.65 \pm 0.22$ & $11.36 \pm 0.34$ & $12.83 \pm 0.34$ & $10.13 \pm 0.35$ & 0.096 & 0.904 \\
\hline $\mathrm{KCl}$ - stripped & 0.251 & 0.295 & 0.184 & 0.291 & 0.364 & 0.309 & 0.279 & 0.329 & 0.671 & 0.329 \\
\hline DPG - stripped & 0.230 & 0.180 & 0.163 & 0.058 & 0.121 & 0.206 & 0.258 & 0.321 & 0.726 & 0.274 \\
\hline$(\mathrm{KCl}+\mathrm{DPG})-$ stripped & d 0.262 & 0.246 & 0.247 & 0.117 & 0.164 & 0.316 & 0.308 & 0.348 & 0.214 & 0.786 \\
\hline
\end{tabular}


tially restored by $\mathrm{H} \rightarrow \mathrm{L}$ substitutions at these same loci (Figure 1B). In principle, a suppressed DPG sensitivity (and hence, increased $\mathrm{Hb}-\mathrm{O}_{2}$ affinity) could be produced by charge-changing amino acid replacements that eliminate phosphate-binding sites in the $\beta$-chain subunits. Because the positively charged phosphate-binding sites are invariant in deer mouse $\beta$ chains $(17,18)$, allelic variation in DPG sensitivity must stem from indirect, second-order perturbations.

Analysis of the crystal structure of deer mouse $\mathrm{Hb}$ at $1.8 \AA$ resolution $(24,25)$ revealed that each of the eight $\mathrm{rHb}$ mutants is characterized by a unique constellation of hydrogen bonds within and between subunits (Table 2 and Figure S2). Additional hydrogen bonds between subunits of the same $\alpha \beta$ dimer are formed in the presence of $\beta 128 \mathrm{Ser}$ (an L-type residue; Figure S2), which contributes to the observed epistasis between allelic $\alpha$ - and $\beta$-chain variants. Structural analysis also revealed that in Hbs with L-type $\alpha$-globin, the imidazole ring of $\alpha 50 \mathrm{His}$ forms a hydrogen bond with $\alpha 30$ Glu in the same subunit. The replacement of $\alpha 50 \mathrm{His}$ with Pro (the H-type residue) eliminates this hydrogen bond and causes a subtle reorientation of the E helix and CD loop (Figure 2), an effect that propagates to the $\alpha 1 \beta 2$ intersubunit contact and shifts the allosteric equilibrium in favor of the high-affinity oxyHb (R-state) quaternary structure.

To test the effects of charge-changing $\alpha$-chain mutations in the CD loop ( $\alpha 50 \mathrm{His} /$ Pro) and the adjacent E helix ( $\alpha 64$ Asp/ Gly), we synthesized each of the alternative single and double mutants on both HH-H and LL-L backgrounds. The experiments revealed that, on the LL-L background, substitutions of H-type residues $(\alpha 50 \mathrm{His} \rightarrow$ Pro and $\alpha 64 \mathrm{Asp} \rightarrow$ Gly) did not

Table 2 Allelic variation in the network of atomic contacts within and between subunits of deer mouse $\mathrm{Hb}$. Plus signs denote the presence of hydrogen bonds within subunits ( $\alpha 50 \mathrm{His}-$ a30Glu and $\alpha 113 \mathrm{His}-\alpha 24 \mathrm{Tyr}$ ) or between subunits of unlike type ( $\alpha 34 \mathrm{Cys}-\beta 128 \mathrm{Ser}$ ). Polymorphic sites are shown in bold.

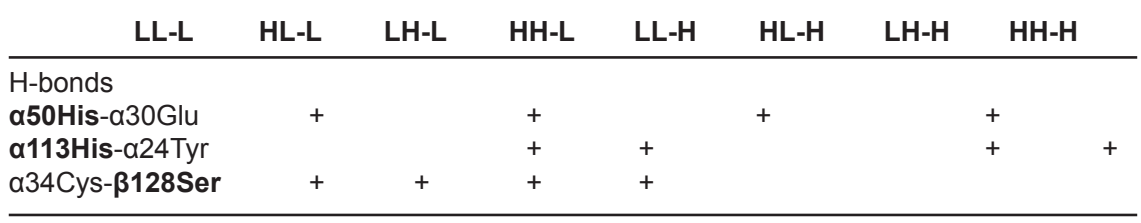

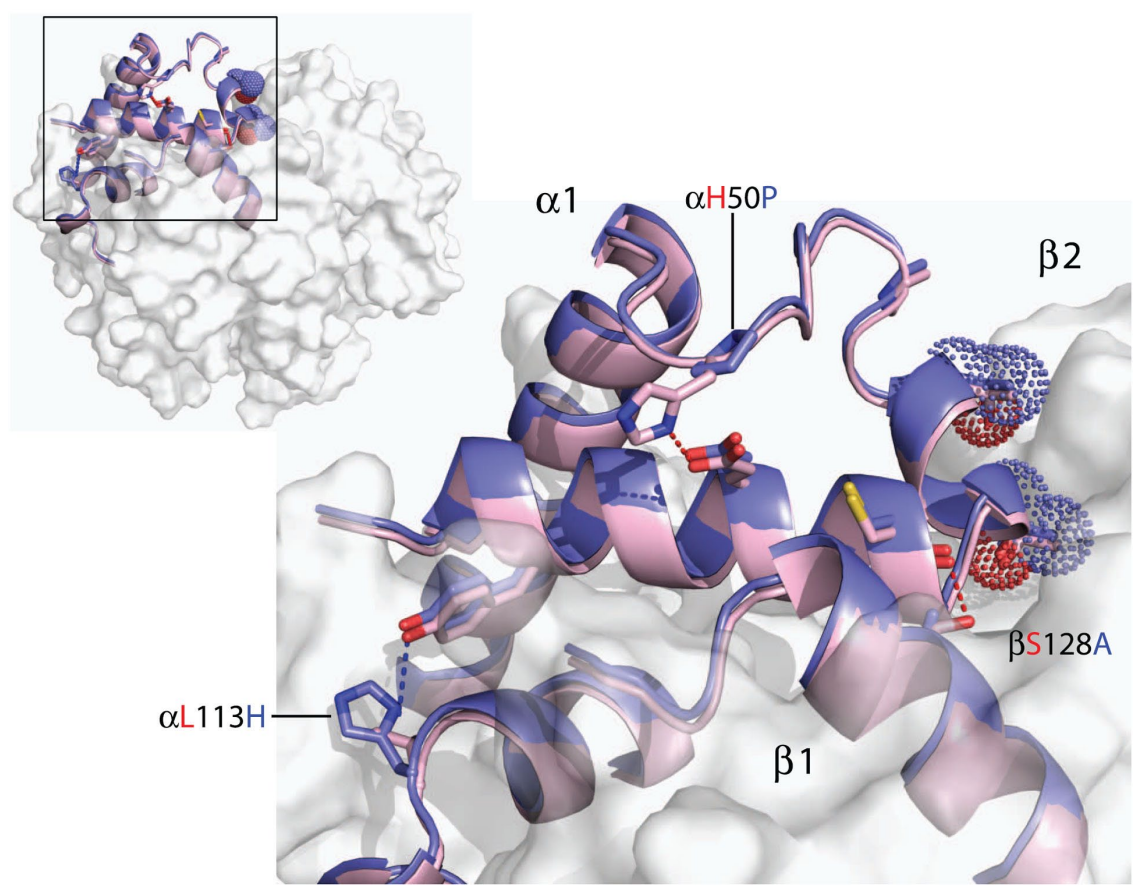

Figure 2. Difference in the network of hydrogen bonds between high- and low-altitude $\mathrm{Hb}$ variants, $\mathrm{HH}-\mathrm{H}$ and $\mathrm{LL}-\mathrm{L}$, respectively. The $\alpha 1$ and $\beta 1$ subunits of $\mathrm{HH}-\mathrm{H}$ (light blue) and $\mathrm{LL}-\mathrm{L}$ (light red) are superimposed, and van der Waals radii are shown for $\alpha$-chain residues that are in atomic contact with $\beta$-chain residues of the opposing $\alpha 2 \beta 2$ dimer.

produce a significant increase in $\mathrm{Hb}-\mathrm{O}_{2}$ affinity individually or in combination; however, on the HH-H background, single-step reversions to L-type residues at both sites produced significant reductions in $\mathrm{Hb}-\mathrm{O}_{2}$ affinity in the presence of allosteric effectors (Figure S3). We also measured the individual effects of all four amino acid mutations in the $\beta$-chain subunit. On the LL-L background, the substitution $\beta 128 \mathrm{Ser} \rightarrow \mathrm{Ala}$, which removes an $\alpha 1 \beta 1$ hydrogen bond (Figure S2), produced an increased anion sensitivity (and hence, a decreased $\mathrm{Hb}-\mathrm{O}_{2}$ affinity in the presence of $\mathrm{Cl}^{-}$and DPG; Figure S4). However, on this same background, introducing all four H-type $\beta$-chain mutations in combination produced a highly significant increase in $\mathrm{Hb}-\mathrm{O}_{2}$ affinity in the presence of allosteric effectors (Figure S4).

In summary, results of our mutagenesis experiments revealed pervasive epistasis among segregating amino acid variants in deer mouse $\mathrm{Hb}$ (Table 1). The individual and joint effects of $\alpha$ - and $\beta$-chain point mutations contribute to the elevated $\mathrm{Hb}-\mathrm{O}_{2}$ affinity of highland deer mice, but the effects of these mutations are highly dependent on the allelic state of other residue positions.

Directed mutagenesis studies have unveiled "cryptic" epistasis between amino acid substitutions that distinguish deeply diverged orthologous proteins $(7,11,13$, 14). Similarly, experimental studies of microbial systems have revealed intragenic epistasis between sites that underwent successive allelic substitutions but that were never simultaneously polymorphic $(6,10)$. By contrast, the interacting mutations in deer mouse $\mathrm{Hb}$ are segregating in natural populations and, given the extensive intragenic and intergenic LD, the epistasis contributes to additive genetic variance in $\mathrm{Hb}$ function, providing an explanation for the previously documented variation in anion sensitivity of deer mouse Hbs (17, 18). Given the evidence for spatially varying selection on $\mathrm{Hb}$ polymorphism in relation to altitude, the pervasiveness of sign epistasis for $\mathrm{Hb}-\mathrm{O}_{2}$ affinity suggests that the selection coefficient for a given allele will often be highly dependent on the allelic composition of the local population. Thus, sign epistasis among segregating amino acid variants may exert a strong influence on allele frequency dynamics and mutational pathways of protein evolution.

Acknowledgments - Funded by grants from the NIH-National Heart, Lung, 
and Blood Institute (R01 HL087216 and HL087216-S1), the NSF (DEB-0614342 and IOS-0949931), and the Faculty of Science and Technology, Aarhus University. We thank S. Kachman for statistical advice, A. Bang for assistance in the lab, and M. Harms, S. Smith, and two reviewers for helpful comments. All experimental data are tabulated in the main text and in the supplementary materials.

\section{Supplementary Materials appear follow- ing References and Notes. \\ Materials and Methods \\ Figs. S1 to S5 \\ Table S1 \\ References (26-41)}

\section{References and Notes}

1. F. J. Poelwijk, D. J. Kiviet, D. M. Weinreich, S. J. Tans, Nature 445, 383 (2007).

2. D. M. Weinreich, R. A. Watson, L. Chao, Evolution 59, 1165 (2005).

3. J. da Silva, M. Coetzer, R. Nedellec, C. Pastore, D. E. Mosier, Genetics 185, 293 (2010).
4. M. A. DePristo, D. M. Weinreich, D. L. Hartl, Nat. Rev. Genet. 6, 678 (2005).

5. D. J. Kvitek, G. Sherlock, PLoS Genet. 7 , e1002056 (2011).

6. E. R. Lozovsky et al., Proc. Natl. Acad. Sci. U.S.A. 106, 12025 (2009).

7. M. Lunzer, S. P. Miller, R. Felsheim, A. M. Dean, Science 310, 499 (2005).

8. D. R. Rokyta et al., PLoS Genet. 7, e1002075 (2011).

9. M. L. Salverda et al., PLoS Genet. 7, e1001321 (2011).

10. D. M. Weinreich, N. F. Delaney, M. A. Depristo, D. L. Hartl, Science 312, 111 (2006).

11. J. T. Bridgham, E. A. Ortlund, J. W. Thornton, Nature 461, 515 (2009).

12. B. Lehner, Trends Genet. 27, 323 (2011).

13. M. Lunzer, G. B. Golding, A. M. Dean, PLoS Genet. 6, e1001162 (2010).

14. E. A. Ortlund, J. T. Bridgham, M. R. Redinbo, J. W. Thornton, Science 317, 1544 (2007).

15. P. C. Phillips, Nat. Rev. Genet. 9, 855 (2008).

16. J. F. Storz, J. Mammal. 88, 24 (2007).
17. J. F. Storz, A. M. Runck, H. Moriyama, R. E. Weber, A. Fago, J. Exp. Biol. 213, 2565 (2010).

18. J. F. Storz et al., Proc. Natl. Acad. Sci. U.S.A. 106, 14450 (2009).

19. M. A. Chappell, J. P. Hayes, L. R. G. Snyder, Evolution 42, 681 (1988).

20. M. A. Chappell, L. R. G. Snyder, Proc. Natl. Acad. Sci. U.S.A. 81, 5484 (1984).

21. J. F. Storz, J. K. Kelly, Genetics 180 , 367 (2008).

22. J. F. Storz, C. Natarajan, Z. A. Cheviron, F. G. Hoffmann, J. K. Kelly, Genetics 190, 203 (2012).

23. J. F. Storz et al., PLoS Genet. 3, e45 (2007).

24. Materials and methods are attached following the References.

25. N. Inoguchi et al., Acta Crystallogr. Sect. F Struct. Biol. Cryst. Commun. 69, 393 (2013). 


\section{Supplementary Materials for}

\section{Epistasis Among Adaptive Mutations in Deer Mouse Hemoglobin}

Chandrasekhar Natarajan, Noriko Inoguchi, Roy E. Weber, Angela Fago, Hideaki Moriyama, Jay F. Storz*

*Corresponding author. E-mail: jstorz2@unl.edu

Published 14 June 2013, Science 340, 1324 (2013)

DOI: $10.1126 /$ science. 1236862

This PDF file includes:

Materials and Methods

Figs. S1 to S5

Table S1

References (26-41) 


\section{Materials and Methods}

Vector construction. Nucleotide sequences of deer mouse globin genes were optimized with respect to $E$. coli codon preferences, and were then synthesized by GenScript (Piscataway, NJ, USA). Gene cassettes for the $\alpha$ - and $\beta$-globin genes and the methionine aminopeptidase (MAP) gene were tandemly cloned into the custom expression vector described by Natarajan et al. (26). In order to maximize efficiency in the posttranslational cleaving of $\mathrm{N}$-terminal methionines from the $\alpha$ - and $\beta$-chain polypeptides, an additional copy of the MAP gene was cloned into the pCO-MAP plasmid with a kanamycin resistance gene and was co-expressed with the pGM expression plasmid.

Mutagenesis. Using the HH-H and LL-L pGM plasmid vector templates, cassette mutagenesis was performed by switching out HH- and L-type sequences of $\alpha$ - and $\beta$ globin genes, thereby yielding the chimeric HH-L and LL-H constructs. To synthesize the remaining constructs, the same plasmids were used as templates for site-directed mutagenesis using the QuikChange ${ }^{\circledR}$ II XL Site-Directed Mutagenesis kit from Stratagene (LaJolla, CA, USA). In each plasmid construct, engineered codon changes were verified by DNA sequencing. Sequences for the mutagenic primers are provided in Table S1 and sequences of the synthesized $\alpha$ - and $\beta$-globin genes are provided in Fig. S5.

Expression and purification of recombinant hemoglobin. All rHbs were expressed in E. coli JM109 (DE3). The bacterial cells were subject to dual selection in an LB agar plate containing ampicillin and kanamycin. This double selection ensures that transformed cells receive both the pGM and pCO-MAP plasmids. Large-scale production was conducted in batches containing 1-1.5 $\mathrm{L}$ of TB medium. Cells were grown at $37^{\circ} \mathrm{C}$ in an orbital shaker at $200 \mathrm{rpm}$ until the absorbance reached 0.6-0.8 at $600 \mathrm{~nm}$. Expression of the $\mathrm{Hb}$ and MAP genes was induced with $0.2 \mathrm{mM}$ IPTG and the cell culture was supplemented with hemin $(50 \mu \mathrm{g} / \mathrm{ml})$ and glucose $(20 \mathrm{~g} / \mathrm{L})$. The cells were then grown at $28^{\circ} \mathrm{C}$ for $16 \mathrm{hr}$ in an orbital shaker at $200 \mathrm{rpm}$. The bacterial culture was saturated with $\mathrm{CO}$ for $15 \mathrm{~min}$ and the cells were harvested by centrifugation. Recombinant Hbs were purified by means of HPLC as described previously (26). To confirm that the absorbance maxima of the purified $\mathrm{rHb}$ samples matched those of native $\mathrm{Hbs}$, we measured absorbance spectra of oxy, deoxy, and CO derivatives at 450-600 $\mathrm{nm}$.

$\mathbf{O}_{2}$ equilibrium experiments. $\mathrm{O}_{2}$-binding equilibria of $\mathrm{rHb}$ solutions $(0.2 \mathrm{mM}$ heme $)$

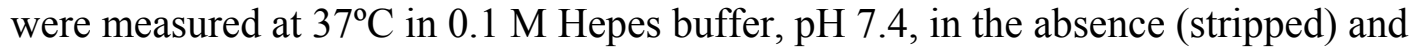
presence of added effectors $(0.1 \mathrm{M} \mathrm{KCl}$, and/or DPG at 2.0-fold molar excess over $\mathrm{rHb}$ tetramers). These are standard experimental conditions $(27,28)$ that closely approximate in vivo effector concentrations: $100 \mathrm{mM} \mathrm{Cl}^{-}$approximates the naturally occurring concentration inside mammalian red blood cells (where $\mathrm{K}^{+}$is the main counter ion, as opposed to $\mathrm{Na}^{+}$in the plasma) and a DPG/Hb tetramer ratio $=2.0$ falls within the physiological range for deer mice and most other eutherian mammals (28-35). Moreover, standardized measurements of purified $\mathrm{Hb}$ are essential for assessing the potentially subtle effects of individual amino acid mutations and for making meaningful comparisons of $\mathrm{Hb}-\mathrm{O}_{2}$ affinity across studies $(27,28,36)$. 
Measurements on purified $\mathrm{Hb}$ solutions in the presence and absence of $\mathrm{Cl}^{-}$and DPG at physiological levels provide insights into mechanisms of allosteric regulation by revealing whether measured differences in $\mathrm{Hb}$ function are attributable to differences in intrinsic $\mathrm{O}_{2}$-affinity and/or differences in sensitivity to anionic effectors $(27,28,37)$. The $\mathrm{rHb}$ concentration used in our $\mathrm{O}_{2}$-equilibrium experiments $(0.2 \mathrm{mM}$ heme $)$ is also standard $(27,28)$.

Measures of $\mathrm{Hb}-\mathrm{O}_{2}$ affinity were conducted using a modified diffusion chamber where changes in absorbance are recorded during stepwise changes in the $\mathrm{O}_{2}$ tension of equilibration gases (36). Each $\mathrm{O}_{2}$-equilibrium curve was based on 4-6 saturation steps. Values of $\mathrm{P}_{50}\left(\mathrm{O}_{2}\right.$ tension at half-saturation $)$ and the cooperativity coefficient, $\mathrm{n}_{50}$, were obtained from the zero-intercept and the slope of Hill plots, respectively: $(\log (Y /(1-Y))$ vs. $\log \mathrm{PO}_{2}$, where $Y$ is the fractional $\mathrm{O}_{2}$ saturation. Standard errors of the measured $\mathrm{P}_{50}$ values were calculated by using nonlinear regression to fit the $\mathrm{O}_{2}$-binding data to the Hill equation. Measured $\mathrm{P}_{50}$ values for the isolated $\mathrm{rHbs}$ were consistent with those for native $\mathrm{Hbs}$ from high- and low-altitude deer mice under identical experimental conditions (1718).

Measuring epistasis. For the set of eight multi-point $\mathrm{rHb}$ mutants, we used a regression model to measure the additive and epistatic components of variance in $\mathrm{P}_{50}$ and $\Delta \log -\mathrm{P}_{50}$ values: $y=\mu+\beta_{1} x_{1}+\beta_{2} x_{2}+\beta_{3} x_{3}+\beta_{12} x_{1} x_{2}+\beta_{13} x_{1} x_{3}+\beta_{23} x_{2} x_{3}+$ error, where coefficients for $\mathrm{x}_{1}, \mathrm{x}_{2}$, and $\mathrm{x}_{3}$ measure the main effects of allelic variants at the three discrete globin modules ( $\alpha$-globin exon $2, \alpha$-globin exon 3 , and $\beta$-globin), and coefficients for $\mathrm{x}_{1} \mathrm{x}_{2}, \mathrm{x}_{1} \mathrm{x}_{3}$, and $\mathrm{x}_{2} \mathrm{x}_{3}$ measure each of the three possible pairwise interaction effects.

To measure pairwise epistasis for $\mathrm{Hb}-\mathrm{O}_{2}$ affinity between a given pair of mutant sites, we measured the epistatic deviation $(\varepsilon)$ from the expectations of an additive model: $\varepsilon=\left(P_{\mathrm{ii}}+P_{\mathrm{jj}}\right)-\left(P_{\mathrm{ij}}+P_{\mathrm{ji}}\right)$, where $P_{\mathrm{ij}}$ is the measured $\mathrm{P}_{50}$ of the $\mathrm{rHb}$ that incorporates the products of alleles $i$ and $j$ at each of two sites. The standard error of the measured epistatic deviation, a linear function of $P_{\mathrm{ij}}$, was calculated using the method of error propagation $\sigma_{\varepsilon}=\sqrt{ } \sigma P_{\mathrm{ii}}{ }^{2}+\sigma P_{\mathrm{jj}}{ }^{2}+\sigma P_{\mathrm{ij}}{ }^{2}+\sigma P_{\mathrm{ji}}{ }^{2}$, and the $95 \%$ confidence interval for $\varepsilon$ was computed as $\varepsilon \pm \sigma_{\varepsilon} \times 1.96$. Epistasis between a given pair of mutant sites was considered to be statistically significant if the $95 \%$ confidence interval for $\varepsilon$ did not include zero.

Structural analysis. To elucidate the structural mechanisms that are responsible for the additive and epistatic effects of the various $\alpha$ - and $\beta$-chain mutations on $\mathrm{Hb}-\mathrm{O}_{2}$ affinity, we used the crystal structure of the LL-L rHb (PDB ID, 4h21) to build a structural model for HH-H using MODELLER 9V11 (38) and SWISS-MODEL (39). Human Hb structures $(2 \mathrm{dn} 1,2 \mathrm{dn} 2$, and $2 \mathrm{dn} 3)$ (40) were used as controls. Molecular interactions were identified by PISA (41), and molecular graphics were generated using PyMol (Schrödinger, LLC). 


\begin{tabular}{|c|c|c|c|c|c|c|c|c|}
\hline (A) $\alpha$-chain variants & 50 & 57 & 60 & 64 & 71 & 113 & 115 & 116 \\
\hline$\alpha^{\mathrm{I}}$ & Pro & Gly & Ala & Gly & Ser & His & Ala & Glu \\
\hline$\alpha^{\mathrm{II}}$ & His & Gly & Ala & Gly & Ser & His & Ala & Glu \\
\hline$\alpha^{\mathrm{III}}$ & Pro & Gly & Ala & Gly & Ser & His & Ala & Asp \\
\hline$\alpha^{\mathrm{IV}}$ & His & Gly & Ala & Gly & Ser & His & Ala & Asp \\
\hline$\alpha^{\mathrm{V}}$ & Pro & Gly & Ala & Gly & Ser & Leu & Ser & Asp \\
\hline$\alpha^{\mathrm{VI}}$ & His & Gly & Ala & Asp & Gly & Leu & Ser & Asp \\
\hline$\alpha^{\mathrm{VII}}$ & His & Ala & Gly & Asp & Gly & Leu & Ser & Asp \\
\hline (B) $\beta$-chain variants & 62 & 72 & 128 & 135 & & & & \\
\hline$\beta^{\mathrm{I}}$ & Gly & Gly & Ala & Ala & & & & \\
\hline$\beta^{\mathrm{II}}$ & Ala & Gly & Ala & Ala & & & & \\
\hline$\beta^{\mathrm{III}}$ & Ala & Ser & Ser & Ser & & & & \\
\hline
\end{tabular}

Fig. S1. Amino acid combinations that define the most common $\alpha$ - and $\beta$-chain $\mathrm{Hb}$ variants in highland and lowland deer mice. (A) Seven allelic $\alpha$-globin variants defined by different 8 -site amino acid combinations. The $\alpha^{\mathrm{I}}$ sequence represents the most common $\alpha$-chain variant in highland mice, and the $\alpha^{\mathrm{VII}}$ sequence represents the most common variant in lowland mice. (B) Three allelic $\beta$-globin variants defined by different 4 -site amino acid combinations. The $\beta^{\mathrm{I}}$ sequence represents the most common $\beta$-chain variant in highland mice, and the $\beta^{\mathrm{III}}$ sequence represents the most common variant in lowland mice. Characteristic H- and L-type allelic variants are shown in blue and red, respectively. 


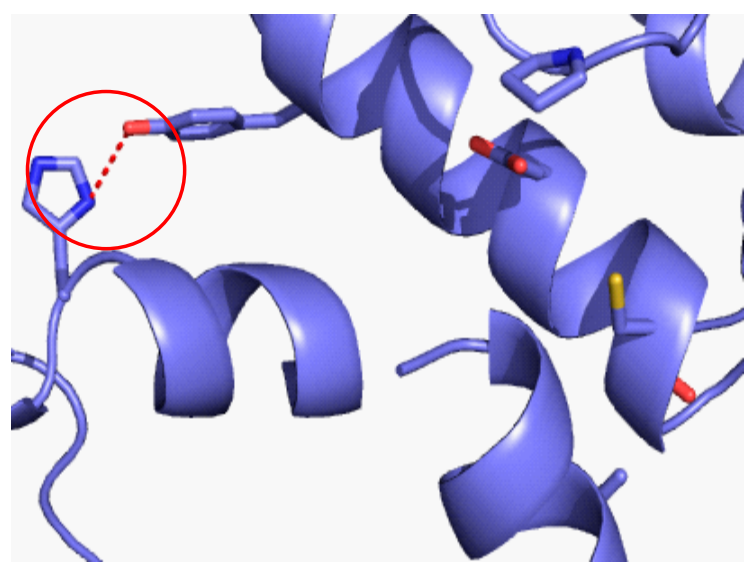

A) HH-H ( $\alpha 113 \mathrm{H}-\alpha 24 \mathrm{Y})$

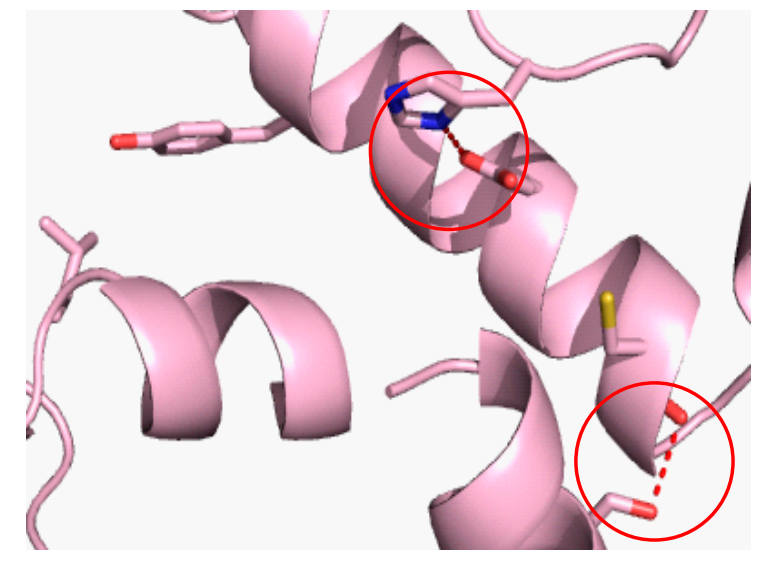

B) LL-L ( $\alpha 50 \mathrm{H}-\alpha 30 \mathrm{E}, \beta 128 \mathrm{~S}-\alpha 34 \mathrm{C})$

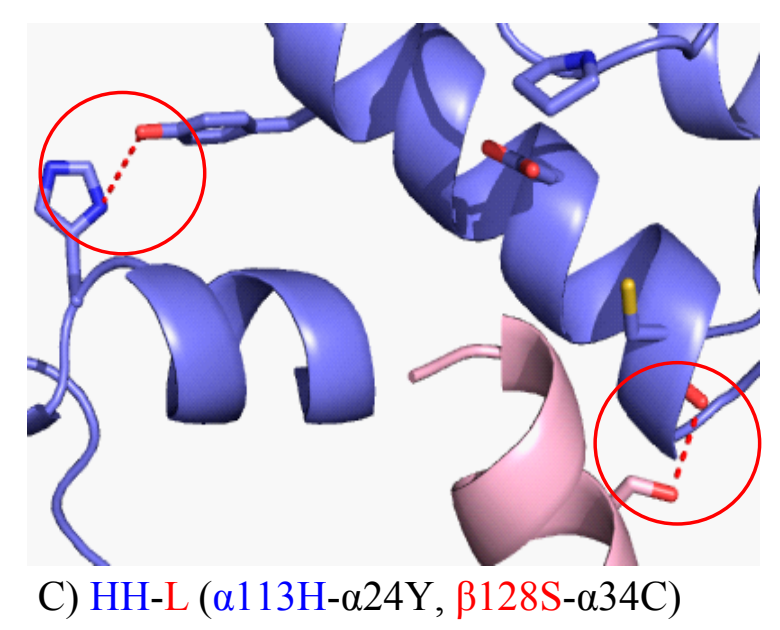

C) HH-L ( $\alpha 113 \mathrm{H}-\alpha 24 \mathrm{Y}, \beta 128 \mathrm{~S}-\alpha 34 \mathrm{C})$

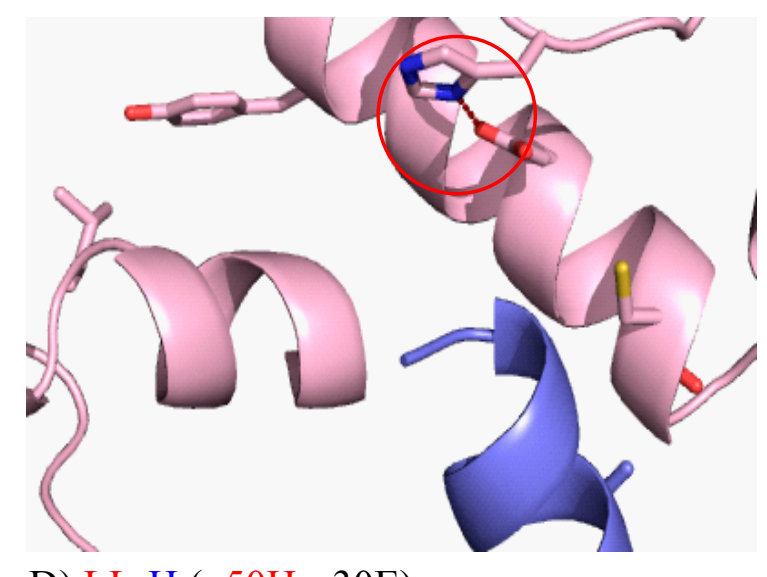

D) LL-H ( $\alpha 50 \mathrm{H}-\alpha 30 \mathrm{E})$

Fig. S2. Presence and absence of hydrogen-bonds in the two most common high- and low-altitude $\mathrm{Hb}$ variants (HH-H and LL-L, respectively) and hybrid tetramers (HH-L and LL-H). The $\alpha 50$ His- $\alpha 30$ Glu bond (depicted in B and D) and the $\alpha 113$ His- $\alpha 24$ Tyr bond (depicted in A and C) represent points of contact between $\alpha$-helices or interhelical loops within the same $\alpha$-chain subunit. The $\alpha 34$ Cys- $\beta 128$ Ser bond (depicted in B and C) represents an intradimer $(\alpha 1 \beta 1$ and $\alpha 2 \beta 2)$ contact. For each polymorphic amino acid site, the alphanumerical designation for each variant residue is shown in blue or red depending on whether it represents a high-altitude (H-type) or low-altitude (L-type) variant, respectively. 

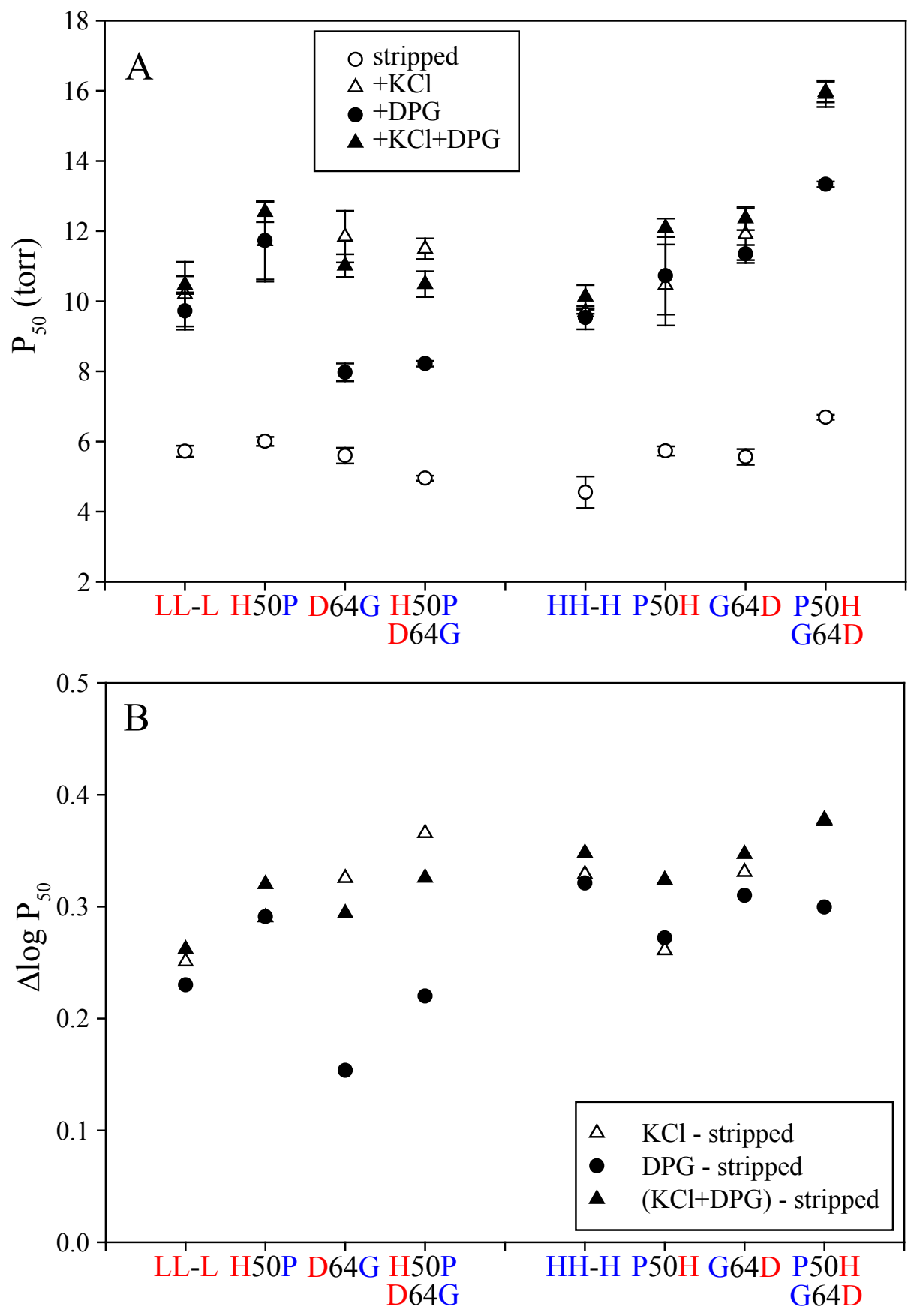

Fig. S3. Individual and pairwise effects of charge-changing $\alpha$-chain mutations on alternative genetic backgrounds. In forward mutagenesis experiments using the LL-L background, H-type mutations were introduced individually (H50P and D64G) and in combination (H50P/D64G). In reverse mutagenesis experiments using the $\mathrm{HH}-\mathrm{H}$ background, both sites were reverted to L-type residues individually (P50H and G64D) and in combination (P50H/G64D). (A) Variation in $\mathrm{P}_{50}$ values in the presence and absence of allosteric effectors ( $\mathrm{Cl}^{-}$and DPG). Error bars represent $95 \%$ confidence intervals. (B) Variation in the sensitivity to allosteric effectors, as indexed by the logtransformed difference in $\mathrm{P}_{50}$ values in the presence and absence of each effector individually and in combination (see text for details). 

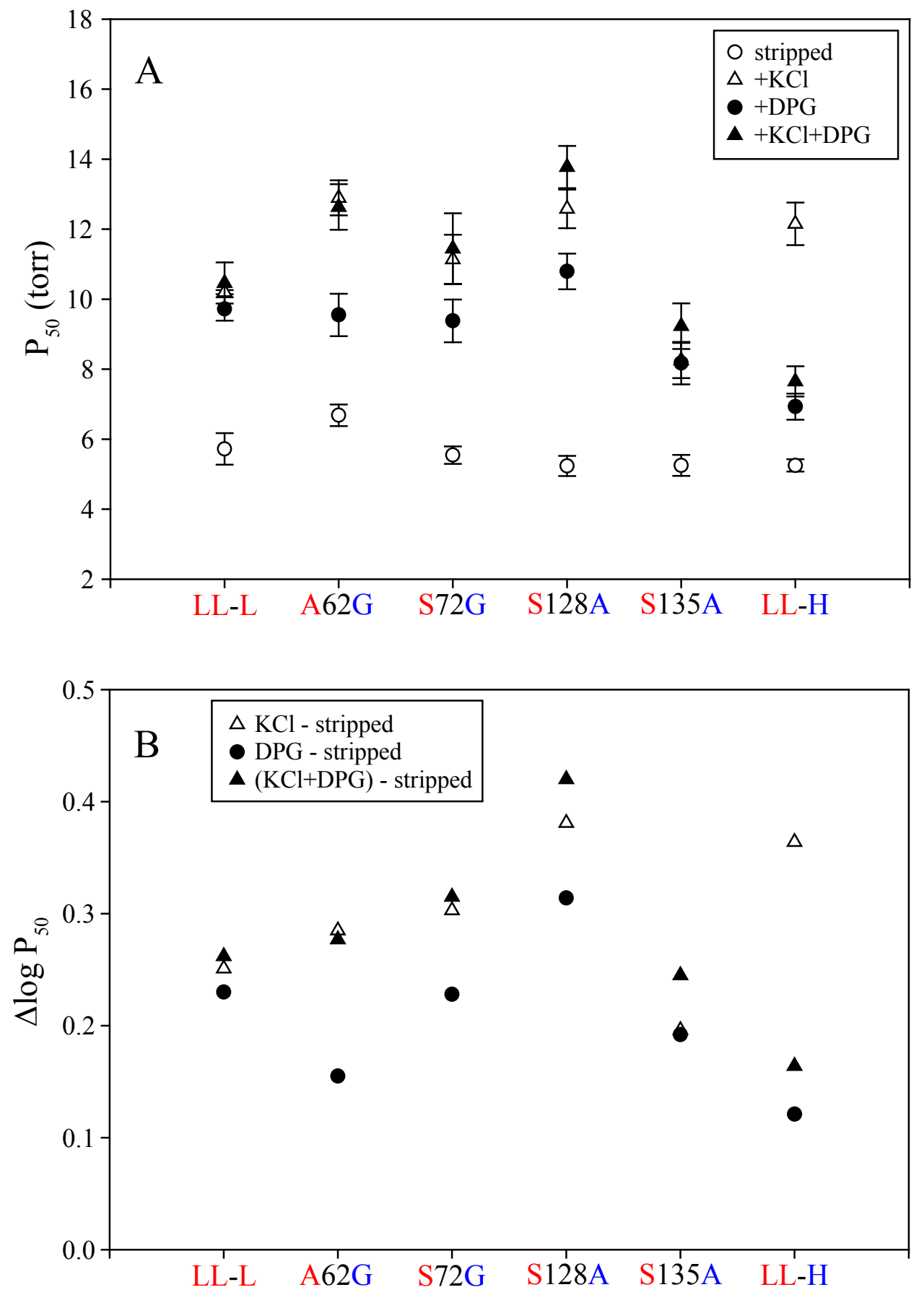

Fig. S4. Individual and combined effects of $\beta$-globin point mutations on the LL-L background. Comparison between 'LL-L' and 'LL-H' reveals the net effect of all four $\beta$ chain mutations in combination. (A) Variation in $\mathrm{P}_{50}$ values in the presence and absence of allosteric effectors ( $\mathrm{Cl}^{-}$and DPG). Error bars represent $95 \%$ confidence intervals. (B) Variation in the sensitivity to allosteric effectors, as indexed by the log-transformed difference in $\mathrm{P}_{50}$ values in the presence and absence of each effector individually and in combination (see text for details). 
A) $\alpha$-globin

1

20

$20 \quad 30$

40

50

60

70

$\alpha \mathrm{HH}$ VLSADDKAN IK AAWGK IGGHG AEYGAEALER MFCS FPTTK TYF PH EVV PGS AQVKGHG AKV AGALATAASHLDD

$\alpha$ HL VLSADDKAN IK AAWGK IGGHG AEYGAEALER MFCS FPTTK TYF PHF DVS PGS AQVKGHG AKV AGALATAASHLDD

$\alpha$ LH VLSADDKAN IK AAWGK IGGHG AEYGAEALER MFCS FPTT TYF PH F DVSHGS AQVK AHG GKV ADALATAAGHLDD

$\alpha$ LL VLSADDKAN IK AAWGKIGGHG AEYGAEALER MFCS PTTK TYF PHFDVSHGS AQVK AHG GKV ADALATAAGHLDD

$$
80
$$

90
1

100

110

120

130

141

$\alpha \mathrm{HH}$ LPAALSALSDLHAHKLRVDPVNFK LLSHCLLV TLAAHHPAEFTPAVHAS LDK FLASVS TVLTSK YR

$\alpha$ HL LPAALSALSDLHAHKLRVDPVNFK

$\alpha$ LH LPAALSALS DLHAHKLRVDPVNEK

$\alpha$ LL LPAA LSA LSDLHAHKLRVDPVNFK

LLSHCLLV TLAAH LPS DFTPAVHAS LDK FLASVS TVLTSK YR

LLSHCLLV TLAAHH P AEFTPAVHAS LDK FLASVS TV L TSK YR

B) $\beta$-globin
1 10 20 30 40 50

60

70

$\beta \mathrm{H} \quad$ VHLTDAEKALVTGLWGKVKPEETGGEAIG

$\beta$ L VHLTDAEKALVTGLWGKVK PEEIGGEALG 80 90 100

RLLAVYPWTQR FEDS FG DLS S AS A IMGN AKVKGHGKKV I DS FGEG L RLLAVYPWTQR FDS FGDLSS AS A IMGN AKVKAHGKKVIDS FS EG L

$\beta H \quad$ KHLDNLKGTFAS LS ELHCDKLHVDPENFK LLGNMIV IVMAHH LGKDFTPAAQAAYQKVVAGVATALAHKYH 1110

120

130

140

146

$\beta$ L KHLDNLKGTFAS LS ELHCDK LHVDPEN FK LLGNMIV IVMAHH LGKDFTPAAQS AYQKVVSGVATALAHKYH

Fig. S5. Amino acid sequences of globin alleles that were incorporated in recombinant deer mouse Hbs. The sequences represent (A) the four alternative $\alpha$-globin variants (HH, HL, LH, and LL) and (B) the two alternative $\beta$-globin variants $(\mathrm{H}$ and $\mathrm{L})$. $\mathrm{H}$ - and L-type residues at variable sites are shown in blue and red, respectively. Spaces in each sequence alignment separate regions that are encoded by exons 1-3. 
Table S1. Sequences of PCR primers used for site-directed mutagenesis.

$\begin{array}{ll}\text { Name } & \text { Primer sequence } \\ \text { LLA62G_SEN } & \text { atcatgggtaacgctaaagttaaaggtcacggtaaaaagttatc } \\ \text { LLA62G_ANTI } & \text { gataactttttaccgtgacctttaactttagcgttacccatgat } \\ \text { LLS72G_SEN } & \text { taaaaagttatcgactctttcggtgaaggtctgaaacacctggac } \\ \text { LLS72G_ANTI } & \text { gtccaggtgtttcagaccttcaccgaaagagtcgataacttttta } \\ \text { LLS128A_SEN } & \text { ccccggctgctcaggctgcttaccagaaag } \\ \text { LLS128A_ANTI } & \text { ctttctggtaagcagcctgagcagccgggg } \\ \text { LLS135A_SEN } & \text { agtctgcttaccagaaagttgttgctggtgttgctac } \\ \text { LLS135A_ANTI } & \text { gtagcaacaccagcaacaactttctggtaagcagact } \\ \text { LSD_SEN } & \text { ctggctgctcacctcccgagtgatttcaccccggctg } \\ \text { LSD_ANTI } & \text { cagccggggtgaaatcactcgggaggtgagcagccag } \\ \text { HAE_SEN } & \text { ctggctgctcaccatccggctgagttcacccggctg } \\ \text { HAE_ANTI } & \text { cagccggggtgaactcagccggatggtgagcagccag } \\ \text { HHP50H_SEN } & \text { ccgcacttcgacgtttctcatggttctgctcaggttaaag } \\ \text { HHP50H_ANTI } & \text { ctttaacctgagcagaaccatgagaaacgtcgaagtgcgg } \\ \text { HHG65D_SEN } & \text { gtgctaaagttgctgatgctctggctaccgc } \\ \text { HHG65D_ANTI } & \text { gcggtagccagagcatcagcaactttagcac } \\ \text { LLH50P_SEN } & \text { cacttcgacgtttctcccggttctgctcaggtt } \\ \text { LLH50P_ANTI } & \begin{array}{l}\text { aacctgagcagaaccgggagaaacgtcgaagtg } \\ \text { gtggtaaagttgctggcgctctggctaccgc }\end{array} \\ \text { LLD64G_SEN } & \text { gcggtagccagagcgccagcaactttaccac } \\ \text { LLD64G_ANTI } & \end{array}$




\section{References and Notes}

1. F. J. Poelwijk, D. J. Kiviet, D. M. Weinreich, S. J. Tans, Empirical fitness landscapes reveal accessible evolutionary paths. Nature 445, 383-386 (2007). doi:10.1038/nature05451 Medline

2. D. M. Weinreich, R. A. Watson, L. Chao, Perspective: Sign epistasis and genetic constraint on evolutionary trajectories. Evolution 59, 1165-1174 (2005). Medline

3. J. da Silva, M. Coetzer, R. Nedellec, C. Pastore, D. E. Mosier, Fitness epistasis and constraints on adaptation in a human immunodeficiency virus type 1 protein region. Genetics $\mathbf{1 8 5}$, 293-303 (2010). doi:10.1534/genetics.109.112458 Medline

4. M. A. DePristo, D. M. Weinreich, D. L. Hartl, Missense meanderings in sequence space: A biophysical view of protein evolution. Nat. Rev. Genet. 6, 678-687 (2005). doi:10.1038/nrg1672 Medline

5. D. J. Kvitek, G. Sherlock, Reciprocal sign epistasis between frequently experimentally evolved adaptive mutations causes a rugged fitness landscape. PLoS Genet. 7, e1002056 (2011). doi:10.1371/journal.pgen.1002056 Medline

6. E. R. Lozovsky, T. Chookajorn, K. M. Brown, M. Imwong, P. J. Shaw, S.

Kamchonwongpaisan, D. E. Neafsey, D. M. Weinreich, D. L. Hartl, Stepwise acquisition of pyrimethamine resistance in the malaria parasite. Proc. Natl. Acad. Sci. U.S.A. 106, 12025-12030 (2009). doi:10.1073/pnas.0905922106 Medline

7. M. Lunzer, S. P. Miller, R. Felsheim, A. M. Dean, The biochemical architecture of an ancient adaptive landscape. Science 310, 499-501 (2005). doi:10.1126/science.1115649 Medline

8. D. R. Rokyta, P. Joyce, S. B. Caudle, C. Miller, C. J. Beisel, H. A. Wichman, Epistasis between beneficial mutations and the phenotype-to-fitness Map for a ssDNA virus. PLoS Genet. 7, e1002075 (2011). doi:10.1371/journal.pgen.1002075 Medline

9. M. L. Salverda, E. Dellus, F. A. Gorter, A. J. Debets, J. van der Oost, R. F. Hoekstra, D. S. Tawfik, J. A. de Visser, Initial mutations direct alternative pathways of protein evolution. PLoS Genet. 7, e1001321 (2011). doi:10.1371/journal.pgen.1001321 Medline

10. D. M. Weinreich, N. F. Delaney, M. A. Depristo, D. L. Hartl, Darwinian evolution can follow only very few mutational paths to fitter proteins. Science 312, 111-114 (2006). doi:10.1126/science.1123539 Medline

11. J. T. Bridgham, E. A. Ortlund, J. W. Thornton, An epistatic ratchet constrains the direction of glucocorticoid receptor evolution. Nature 461, 515-519 (2009). doi:10.1038/nature08249 $\underline{\text { Medline }}$

12. B. Lehner, Molecular mechanisms of epistasis within and between genes. Trends Genet. 27, 323-331 (2011). doi:10.1016/j.tig.2011.05.007 Medline

13. M. Lunzer, G. B. Golding, A. M. Dean, Pervasive cryptic epistasis in molecular evolution. PLoS Genet. 6, e1001162 (2010). doi:10.1371/journal.pgen.1001162 Medline

14. E. A. Ortlund, J. T. Bridgham, M. R. Redinbo, J. W. Thornton, Crystal structure of an ancient protein: Evolution by conformational epistasis. Science 317, 1544-1548 (2007). $\underline{\text { doi:10.1126/science.1142819 Medline }}$ 
15. P. C. Phillips, Epistasis - the essential role of gene interactions in the structure and evolution of genetic systems. Nat. Rev. Genet. 9, 855-867 (2008). doi:10.1038/nrg2452 Medline

16. J. F. Storz, Hemoglobin function and physiological adaptation to hypoxia in high-altitude mammals. J. Mammal. 88, 24-31 (2007). doi:10.1644/06-MAMM-S-199R1.1

17. J. F. Storz, A. M. Runck, H. Moriyama, R. E. Weber, A. Fago, Genetic differences in hemoglobin function between highland and lowland deer mice. J. Exp. Biol. 213, $2565-$ 2574 (2010). doi:10.1242/jeb.042598 Medline

18. J. F. Storz, A. M. Runck, S. J. Sabatino, J. K. Kelly, N. Ferrand, H. Moriyama, R. E. Weber, A. Fago, Evolutionary and functional insights into the mechanism underlying highaltitude adaptation of deer mouse hemoglobin. Proc. Natl. Acad. Sci. U.S.A. 106, 14450 14455 (2009). doi:10.1073/pnas.0905224106 Medline

19. M. A. Chappell, J. P. Hayes, L. R. G. Snyder, Hemoglobin polymorphisms in deer mice (Peromyscus maniculatus): Physiology of beta-globin variants and alpha-globin recombinants. Evolution 42, 681 (1988). doi:10.2307/2408859

20. M. A. Chappell, L. R. G. Snyder, Biochemical and physiological correlates of deer mouse alpha-chain hemoglobin polymorphisms. Proc. Natl. Acad. Sci. U.S.A. 81, 5484-5488 (1984). doi:10.1073/pnas.81.17.5484 Medline

21. J. F. Storz, J. K. Kelly, Effects of spatially varying selection on nucleotide diversity and linkage disequilibrium: Insights from deer mouse globin genes. Genetics 180, 367-379 (2008). doi:10.1534/genetics.108.088732 Medline

22. J. F. Storz, C. Natarajan, Z. A. Cheviron, F. G. Hoffmann, J. K. Kelly, Altitudinal variation at duplicated $\beta$-globin genes in deer mice: Effects of selection, recombination, and gene conversion. Genetics 190, 203-216 (2012). doi:10.1534/genetics.111.134494 Medline

23. J. F. Storz, S. J. Sabatino, F. G. Hoffmann, E. J. Gering, H. Moriyama, N. Ferrand, B. Monteiro, M. W. Nachman, The molecular basis of high-altitude adaptation in deer mice. PLoS Genet. 3, e45 (2007). doi:10.1371/journal.pgen.0030045 Medline

24. Materials and methods are available as supplementary materials on Science Online.

25. N. Inoguchi, J. R. Oshlo, C. Natarajan, R. E. Weber, A. Fago, J. F. Storz, H. Moriyama, Deer mouse hemoglobin exhibits a lowered oxygen affinity owing to mobility of the E helix. Acta Crystallogr. Sect. F Struct. Biol. Cryst. Commun. 69, 393-398 (2013). doi:10.1107/S1744309113005708 Medline

26. C. Natarajan, X. Jiang, A. Fago, R. E. Weber, H. Moriyama, J. F. Storz, Expression and purification of recombinant hemoglobin in Escherichia coli. PLoS ONE 6, e20176 (2011). doi:10.1371/journal.pone.0020176 Medline

27. K. Imai, Allosteric Effects in Hemoglobin (Cambridge Univ. Press, Cambridge, UK, 1982).

28. H. Mairbäurl, R. E. Weber, Compr. Physiol. 2, 1463 (2011). doi:10.1002/cphy.c080113

29. R. Baumann, C. Bauer, H. Bartels, Influence of chronic and acute hypoxia on oxygen affinity and red cell 2,3 diphosphoglycerate of rats and guinea pigs. Respir. Physiol. 11, 135-144 (1971). doi:10.1016/0034-5687(71)90018-1 Medline 
30. H. F. Bunn, Differences in the interaction of 2,3-diphosphoglycerate with certain mammalian hemoglobins. Science 172, 1049-1050 (1971). doi:10.1126/science.172.3987.1049 Medline

31. J. Duhm, Effects of 2,3-diphosphoglycerate and other organic phosphate compounds on oxygen affinity and intracellular $\mathrm{pH}$ of human erythrocytes. Pflugers Arch. 326, 341-356 (1971). doi:10.1007/BF00586998 Medline

32. J. Duhm, E. Gerlach, On the mechanisms of the hypoxia-induced increase of 2,3diphosphoglycerate in erythrocytes. Pflugers Arch. 326, 254-269 (1971). doi:10.1007/BF00592506 Medline

33. H. Mairbäurl, O. Oelz, P. Bärtsch, Interactions between $\mathrm{Hb}, \mathrm{Mg}$, DPG, ATP, and Cl determine the change in $\mathrm{Hb}-\mathrm{O}_{2}$ affinity at high altitude. J. Appl. Physiol. 74, 40-48 (1993). Medline

34. L. R. G. Snyder, 2,3-diphosphoglycerate in high- and low-altitude populations of the deer mouse. Respir. Physiol. 48, 107-123 (1982). doi:10.1016/0034-5687(82)90053-6 Medline

35. D. M. Tufts, I. G. Revsbech, Z. A. Cheviron, R. E. Weber, A. Fago, J. F. Storz, Phenotypic plasticity in blood-oxygen transport in highland and lowland deer mice. J. Exp. Biol. 216, 1167-1173 (2013). doi:10.1242/jeb.079848 Medline

36. R. E. Weber, Use of ionic and zwitterionic (Tris/BisTris and HEPES) buffers in studies on hemoglobin function. J. Appl. Physiol. 72, 1611-1615 (1992). Medline

37. M. F. Perutz, Mechanisms of cooperativity and allosteric regulation in proteins. Q. Rev. Biophys. 22, 139-237 (1989). doi:10.1017/S0033583500003826 Medline

38. A. Šali, T. L. Blundell, Comparative protein modelling by satisfaction of spatial restraints. $J$. Mol. Biol. 234, 779-815 (1993). doi:10.1006/jmbi.1993.1626 Medline

39. K. Arnold, L. Bordoli, J. Kopp, T. Schwede, The SWISS-MODEL workspace: A web-based environment for protein structure homology modelling. Bioinformatics 22, 195-201 (2006). doi:10.1093/bioinformatics/bti770 Medline

40. S. Y. Park, T. Yokoyama, N. Shibayama, Y. Shiro, J. R. Tame, 1.25 A resolution crystal structures of human haemoglobin in the oxy, deoxy and carbonmonoxy forms. J. Mol. Biol. 360, 690-701 (2006). doi:10.1016/j.jmb.2006.05.036 Medline

41. E. Krissinel, K. Henrick, Inference of macromolecular assemblies from crystalline state. $J$. Mol. Biol. 372, 774-797 (2007). doi:10.1016/j.jmb.2007.05.022 Medline 